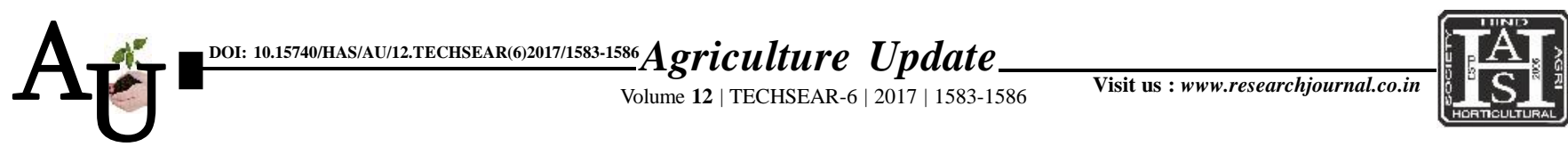

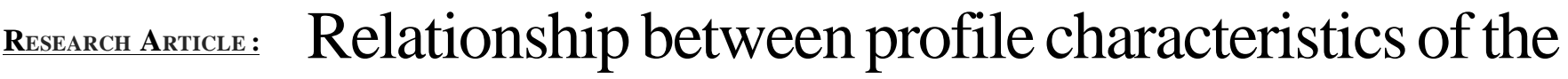 farmers and their perception towards information Kiosk in Thiruvananthapuram district, Kerala
}

Article Chronicle : Received : 17.07.2017;

Accepted : 01.08 .2017

KEY WoRds : Perception, Information Kiosk, Effectiveness, Awareness, Information, Communication technology
Author for correspondence :

\section{N.A. HINDUJA}

Department of

Agricultural Extension, S.V. Agricultural College (A.N.G.R.A.U.), TIRUPATI (A.P.) INDIA

Email: nethaarunhinduja @ gmail.com

\section{N.A. HINDUJA, N. KISHORE KUMAR, R. PRAKASH AND ALLAN THOMAS}

SUMMARY : Advantages of Information and Communication Technologies ICT's can be extended to the disordered and impeded farming community by accomplishing theiraccess to ICT' $\mathrm{s}$ to farmers through Information Kiosks and utilizing them as a stage for spreading of farm innovations which had already been begun in different states through different undertakings. The study revealed that majority of the farmers obtaining information from the Information Kiosks reported medium perception $(55.00 \%)$ of the messages followed by low perception $(10.00 \%)$ and high perception $(8.00 \%)$. Relationship between the profile characteristics and the perception of the farmers about Information Kiosk indicated that effectiveness of Information Kiosk, awareness about Information Kiosk and information dissemination ways by the farmers utilizing the Information Kioskis positively correlated with the Perception of the farmers towards Information Kiosk.

How to cite this article : Hinduja, N.A., Kumar, N. Kishore, Prakash, R. and Thomas, Allan (2017). Relationship between profile characteristics of the farmers and their perception towards information Kiosk in Thiruvananthapuram district, Kerala. Agric. Update, 12(TECHSEAR-6) : 1583-1586; DOI: 10.15740/HAS/AU/ 12. TECHSEAR(6)2017/1583-1586. 